\title{
Improving Reading and Writing Ability of Beginning With The Cooperative Integrated Reading and Composition Method
}

\author{
Siti Maskanah \\ Universitas Sebelas Maret \\ sitimaskanah@gmail.com
}

Article History

accepted 14/11/2020

\begin{abstract}
Reading is an asset for someone to study books and find written information. Reading for a student is also an asset so that they can participate in learning activities. This study aims to improve reading and writing skills beginning with the Cooperative Integrated Reading and Composition (CIRC) learning method. Besides that, it can also improve the ability to read and write at the beginning. This study uses the Cooperative Integrated Reading Composition (CIRC) learning method, this method is one of the integrated cooperative learning methods of reading and writing, where students are divided into several groups to improve their comprehension skills in reading, writing, understanding vocabulary and language arts. This research is able to improve the ability to read and write at the beginning.
\end{abstract}

Keywords: Preliminary writing skill, CIRC method

\begin{abstract}
Abstrak
Membaca adalah modal bagi seseorang untuk mempelajari buku dan mencari informasi tertulis. Membaca bagi seorang siswa juga menjadi modal agar dapat mengikuti kegiatan pembelajaran. Penelitian ini bertujuan meningkatkan keterampilan membaca dan menulis permulaan dengan metode pembelajaran Cooperative Integrated Reading and Composition (CIRC). Selain itu juga dapat meningkatkan kemampuan membaca dan menulis permulaan. Penelitian ini menggunakan metode pembelajaran Cooperative Integrated Reading Composition (CIRC), metode ini adalah salah satu metode pembelajaran kooperatif terpadu membaca dan menulis, dimana peserta didik dibagi menjadi beberapa kelompok untuk meningkatkan kemampuan pemahaman dalam membaca, menulis, memahami kosa kata dan seni berbahasa. Penelitian ini mampu meningkat kemampuan membaca dan menulis permulaan.
\end{abstract}

Kata Kunci :Keterampilan menulis permulaan, metode CIRC

Social, Humanities, and Education Studies (SHEs): Conference Series https://jurnal.uns.ac.id/shes 


\section{PENDAHULUAN}

Membaca adalah modal bagi seseorang untuk mempelajari buku dan mencari informasi tertulis. Membaca bagi seorang siswa juga menjadi modal agar dapat mengikuti kegiatan pembelajaran. Henry Guntur Tarigan berpendapat bahwa "Membaca adalah suatu proses yang dilakukan serta dipergunakan oleh pembaca untuk memperoleh pesan yang hendak disampaikan oleh penulis melalui media katakata atau bahasa tulis". Jika hal ini tidak terpenuhi, maka pesan yang tersurat dan tersirat tidak akan tertangkap atau dipahami dan proses membaca itu tidak terlaksana dengan baik.

Selain membaca, menulis juga harus dikuasai oleh siswa agar siswa dapat mengikuti pembelajaran dengan lancar. Karena itu, kemampuan membaca dan menulis bagi siswa menjadi modal utama untuk dapat mengikuti kegiatan belajar mengajar atau kegiatan pembelajaran. Membaca dan menulis merupakan dasar bagi seseorang untuk dapat melakukan komunikasi secara tertulis. Komunikasi merupakan satu hal yang penting bagi manusia untuk dapat tetap bertahan hidup dan bermasyarakat. Tanpa komunikasi, manusia tidak akan dapat memenuhi hidupnya sendiri. Karena itulah komunikasi sangat penting bagi manusia dalam menjalani hidup di dunia ini. Salah satu bekal untuk dapat berkomunikasi manusia harus dapat membaca dan menulis.

Pembelajaran membaca dan menulis permulaan merupakan bagian dari pembelajaran bahasa. Bahasa merupakan alat penting bagi manusia untuk komunikasi antar anggota masyarakat yang berupa sistem, lambang bunyi yang bermakna dan dihasilkan oleh alat ucap manusia.Di dalam mata pelajaran Bahasa Indonesia di kelas II banyak materi yang harus dipelajari oleh siswa, Salah satunya adalah membaca permulaan. Tahap keterampilan membaca permulaan umumnya terjadi pada saat anak-anak duduk di kelas satu dan dua. Membaca permulaan diadakan untuk mendapatkan informasi tentang kemampuan siswa mengenal dan menyuarakan lambang-lambang bunyi dalam hubungan kalimat dengan intonasi yang wajar. Selain itu dalam keterampilan menulis permulaan mencakup dengan menulis dengan tangan, mengeja, menulis kalimat sederhana dan mengarang. Menulis dengan tangan disebut juga menulis permulaan dan karena menulis terkait erat dengan membaca, maka pelajaran membaca dan menulis di kelas-kelas permulaan sering disebut juga pelajaran membaca dan menulis permulaan.

Pembelajaran Bahasa Indonesia hingga saat ini belum menampakkan hasil yang maksimal. Banyak siswa yang tidak dapat menggunakan Bahasa Indonesia dengan baik dan benar. Berbagai upaya telah dilakukan oleh guru untuk memberi bekal pengetahuan membaca serta pelatihan membaca, namun kenyataan menunjukkan bahwa sampai sekarang ini khususnya di dalam kemampuan membaca dan menulis permulaan tidak sesuai dengan harapan. Beberapa faktor yang menjadi penyebab kesulitan siswa dalam membaca dan menulis adalah siswa kurang berlatih dalam membaca dan sering memperlihatkan kebiasaan yang tidak wajar seperti adanya gerakan-gerakan yang penuh ketegangan, mengernyitkan kening, gelisah atau menggigit bibir dan siswa masih sulit dalam membaca dan memahami sebuah teks cerita. Kesulitan siswa dalam belajar menulis yaitu, cara menulis tidak konsisten, tidak mengikuti alur garis yang tepat, proporsional/tidak rapi, terputus-putus salah satunya yaitu di dalam pembelajaran menulis permulaan.

Hasil observasi selama penulis melaksanakan Praktek Pengalaman Lapangan (PPL) di SDN Banjaragung 01 pada kelas II banyak siswa masih memiliki kemampuan 
membaca dan menulis yang rendah. Faktor yang menjadi penyebab siswa mengalami kesulitan dalam belajar membaca dan menulis yaitu siswa kurang latihan, dan kemampuan guru yang masih bersifat konvensional, belum menerapkan pembelajaran yang inovatif, dimana siswa belum berperan aktif dalam kegiatan belajar mengajar. Pembelajaran masih berpusat pada guru, selain itu guru belum mampu menerapkan metode pembelajaran secara maksimal. Oleh karena itu, perlu dilakukan sebuah tindakan pembelajaran dengan metode yang berbeda. Salah satu metode yang dapat digunakan untuk meningkatkan kemampuan membaca dan menulis permulaan adalah dengan metode pembelajaran kooperatif Cooperative Integrated Reading and Composition (CIRC). Karena metode ini dipandang sebagai metode yang tepat untuk meningkatkan keterampilan membaca dan menulis permulaan bagi siswa kelas II SDN Banjaragung 01.

Metode ini dipilih karena fokus pada membaca dan menulis siswa. Melalui metode ini siswa dapat berlatih dalam melaksanakan pembelajaran membaca dan menulis yang diarahkan pada pemahaman membaca, kosakata, pembacaan pesan, dan ejaan. Para siswa termotivasi untuk saling bekerja satu sama lain dalam kegiatan-kegiatan ini. Selain itu metode ini dipilih untuk mengatasi masalah yang timbul dalam mengajarkan wacana pada siswa dan menumbuhkan gagasangagasan pada diri siswa dalam bentuk tulisan.

\section{METODE}

Jenis penelitian ini adalah peneliatian tindakan kelas (Classroom Action Reseach) dengan menerapkan metode pembelajaran kooperatif Cooperative Integrated Reading and Composition (CIRC). Penelitan ini terdiri dari empat tahap dalam setiap siklusnya yang meliputi perencanaan, pelaksanaan, pengamatan dan refleksi. Subjek penelitian ini adalah siswa kelas II SDN Banjaragung 01 yang berjumlah 30 siswa. Siswa laki-laki berjumlah 15 orang dan siswa perempuan berjumlah 15 orang.

\section{HASIL DAN PEMBAHASAN}

Penelitian ini adalah Penelitian Tindakan Kelas. PTK adalah penelitian tindakan yang dilakukan dengan tujuan memperbaiki mutu praktik pembelajaran di kelas. Fokus PTK pada siswa yang terjadi di kelas. Tujuan utama PTK adalah untuk memecahkan permasalahan nyata yang terjadi di kelas dan meningkatkan kegiatan nyata guru dalam kegiatan pengembangan profesinya.

Penelitian ini dilakukan untuk melihat tingkat kemampuan guru dalam mengelola pembelajaran dengan menggunakan metode $C I R C$ pada pembelajaran membaca dan menulis permulaan materi membaca teks cerita, aktivitas siswa serta hasil belajar. Data ini diperoleh dari aktivitas guru dan siswa serta dari tes membaca teks cerita dengan lancar dan menulis permulaan dengan jelas dan rapi. Hasil analisis data terhadap aktivitas guru dan siswa serta hasil belajar diperoleh dari pembelajaran yang berlangsung setelah memenuhi kriteria pembelajaran dengan menggunakan metode CIRC.

Berdasarkan data yang telah dikumpulkan dalam penelitian ini pembahasan untuk setiap siklusnya akan dibahas secara ringkas sebagai berikut:

\section{Analisis Hasil Pengamatan Guru dalam Mengelola Pembelajaran}

Aktivitas pembelajaran yang dilakukan guru dalam menggunakan metode CIRC pada materi membaca teks cerita dari siklus I sampai siklus II mengalamipeningkatan. Skor yang diperoleh pada siklus I adalah dengan nilai persentase $70,68 \%$ (kategori Baik). Hal ini disebabkan karena kemampuan 
guru dalam mengkondisikan kelas, mengaitkan pengalaman siswa dengan materi, dan memotivasi siswa. Guru juga belum mampu meminta setiap kelompok untuk mendiskusikan teks cerita, meminta siswa untuk menentukan akhir cerita, meminta setiap kelompok untuk membuat sinopsis cerita dikarenakan masih banyak siswa dari setiap kelompok belum aktif untuk berdiskusi. Guru kurang memberikan penghargaan terhadap siswa yang telah mempresentasikan hasil diskusi kelompoknya, sehingga menyebabkan siswa kurang termotivasi untuk maju ke depan. Guru juga belum jelas dalam menyimpulkan pembelajaran.

Sedangkan pada siklus II kemampuan guru dalam mengelola pembelajaran dengan menggunakan metode CIRC memperoleh nilai persentase $89,16 \%$ (kategori Sangat Baik). Pada siklus ini kemampuan guru dalam mengelola pembelajaran sudah maksimal. Dengan demikian data tersebut menunjukkan aktivitas guru dalam mengelola pembelajaran dengan menggunakan metode $C I R C$ pada materi membaca teks cerita berada pada kategori Sangat Baik. Aktivitas guru dalam pembelajaran pada kegiatan awal, kegiatan inti, dan kegiatan akhir sudah terlaksana dengan rencana yang telah disusun.

\section{Analisis Hasil Pengamatan Aktivitas Siswa dalam Proses Pembelajaran} dengan

Berdasarkan hasil pengamatan aktivitas siswa dalam pembelajaran menggunakan metode $C I R C$ selama pembelajaran mengalami peningkatan. Pada siklus I nilai persentase yang diperoleh 62,5\% (kategori Baik). Pada siklus I siswa masih kurang merespon dalam berdoa bersama, menjawab absensi, mendengarkan

motivasi, memperhatikan teks cerita yang diberikan guru, siswa belum secara aktif dalam berdiskusi, menjawab pertanyaan yang diajukan guru, siswa kurang berani maju ke depan untuk mempresentasikan hasil diskusi kelompok mereka. Siswa masih belum serius dalam menyimpulkan hasil pembelajaran. Oleh karena itu untuk mengatasi ketidakseriusan siswa dalam belajar sebaiknya guru memberikan motivasi kepada siswa agar mereka lebih serius untuk belajar dan berani mempresentasikan hasil diskusi kelompok mereka.

Sedangkan pada siklus II aktivitas siswa mengalami peningkatan dengan nilai persentase $89,42 \%$ (kategori Sangat Baik). Pada siklus ini siswa sudah mengikuti proses pembelajaran dengan baik. Walaupun ada sebagian siswa kurang memperhatikan pembelajaran. Dengan demikian dapat disimpulkan bahwa penggunaan metode CIRC pada pembelajaran Bahasa Indonesia pada materi membaca teks cerita dapat meningkatkan aktivitas belajar siswa.

\section{Hasil Belajar Siswa Setelah Menerapkan Metode CIRC}

Nilai KKM individual yang ditetapkan di SDN Banjaragung 01 pada pembelajaran Bahasa Indonesia adalah 70. Setiap siswa dikatakan tuntas belajarnya (ketuntasan individu) jika hasil belajar siswa mencapai 70 atau melebihi KKM yang telah ditentukan. Sedangkan ketuntasan klasikal yang ditetapkan sekolah yaitu $75 \%$. Untuk mengetahui kemampuan siswa dalam membaca teks teks dan menulis permulaan dengan jelas dan rapi, maka peneliti melakukan tes pada setiap siklus. Dari hasil tes membaca lancar teks bacaan pada siklus I hanya 19 siswa atau $70,73 \%$ yang dapat membaca dengan lancar, sedangkan 12 siswa atau $29,27 \%$ belum lancar dalam membaca. Dalam tes menulis permulaan hanya 28 siswa atau $68,29 \%$ yang dapat menulis dengan jelas dan rapi. Sedangkan 13 siswa atau 31,71 belum 
rapi dalam menulis dan masih acak-acakan.

Sedangkan hasil tes membaca pada siklus II sudah mulai meningkat menjadi 36 siswa atau $87,80 \%$ sedangkan 5 siswa atau 12,2\% belum lancar dalam membaca. Dan dalam tes menulis permulaan hanya 35 siswa atau $85,36 \%$ sudah mulai rapi dalam menulis, sedangkan 6 siswa atau 14,64\% belum rapi dalam menulis.

Berdasarkan analisa di atas dapat disimpulkan bahwa penerapan metode $C I R C$ dapat meningkatkan kemampuan siswa dalam membaca dan menulis permulaan, yaitu sebanyak 36 siswa atau $87,80 \%$ sudah lancar dalam membaca, dan dalam menulis permulaan 35 siswa atau $85,36 \%$ sudah rapi dalam menulis. Angka ini sudah mencapai ketuntasan secara klasikal yang telah ditetapkan oleh sekolah pada pembelajaran Bahasa Indonesia yaitu $80 \%$. Oleh sebab itu penelitian ini dicukupkan pada siklus II saja. Jadi dapat kita simpulkan bahwa penerapan metode $C I R C$ dapat meningkatkan kemampuan siswa dalam membaca dan menulis permulaan. Hal ini sesuai dengan salah satu kelebihan dari metode $C I R C$ yaitu dapat meningkatkan kemampuan hasil belajar siswa dalam membaca dan menulis permulaan.

\section{SIMPULAN}

Berdasarkan data hasil perbaikan pembelajaran yang telah penulis laksanakan dalam dua siklus, maka dapat kditari kesimpulan bahwa :

1. Aktivitas pembelajaran yang dilakukan guru dalam menggunakan metode $C I R C$ pada materi membaca teks cerita dari siklus I sampai siklus II mengalami peningkatan. Skor yang diperoleh pada siklus I adalah 70,68\% (kategori Baik). Sedangkan pada siklus II memperoleh nilai persentase $89,16 \%$ (kategori Sangat Baik).

2. Penggunaan metode CIRC meningkatkan aktivitas siswa dalam proses pembelajaran. Pada siklus I nilai persentase keaktifan siswa mencapai 62,5\% (kategori Baik). Sedangkan pada siklus II aktivitas siswa mengalami peningkatan dengan nilai persentase $89,42 \%$ (kategori Sangat Baik).

3. Penerapan metode $C I R C$ dapat meningkatkan kemampuan siswa dalam membaca dan menulis permulaan.

- Pada siklus I hanya 19 siswa atau 70,73\% yang dapat membaca dengan lancar, sedangkan 12 siswa atau 29,27\% belum lancar dalam membaca. Dalam tes menulis permulaan hanya 28 siswa atau $68,29 \%$ yang dapat menulis dengan jelas dan rapi. Sedangkan 13 siswa atau 31,71 belum rapi dalam menulis dan masih acak - acakan.

- Sedangkan hasil tes membaca pada siklus II sudah mulai meningkat menjadi 36 siswa atau $87,80 \%$, dan 5 siswa atau 12,2\% belum lancar dalam membaca. Dan dalam tes menulis permulaan hanya 35 siswa atau $85,36 \%$ sudah mulai rapi dalam menulis, sedangkan 6 siswa atau 14,64\% belum rapi dalam menulis.

\section{DAFTAR PUSTAKA}

Agus Suprijono. 2010. Cooperative Learning Teori dan Aplikasi Paikem. Yogyakarta: Pustaka Belajar.

Anas Sudijono. 2006. Pengantar Statistik Pendidikan. Jakarta: Raja Grafindo Persada. 
Anas Sudiyono. 2009. Pengantar Evaluasi Pendidikan. Jakarta: Rajawali Press. Ahmad Susanto. 2013. Teori Belajar dan Pembelajaran di Sekolah Dasar. Jakarta: Kencana Prenada Media Group.

Azwardi. 2007. Pembelajaran Bahasa Indonesia. Banda Aceh: Universitas Syiah Kuala.

Departemen Pendidikan Nasional. 2009. Membaca dan Menulis Permulaan. Jakarta: Departemen Pendidikan Nasional.

Ekaikhsanudin.net, Tujuan Membaca dan Menulis Permulaan, 12 Juni 2010. Diakses pada tanggal 15 Maret 2017 dari situs: www.ekaikhsanudin.net/tujuan- membaca-dan menulis-permulaan.html

E. Mulyasa. 2012. Praktik Penelitian Tindakan Kelas. Bandung: Remaja Rosdakarya. Henri Guntur Tarigan. 1979. Membaca Sebagai Suatu Keterampilan Berbahasa. Bandung: Angkasa.

http://repository.library.uksw.edu/bitsream/handle/123456789/1063/TI 292010 802 BAB\%20ll.pdf?sequence $=3$

Iwanlukman.blogspot.co.id, Model Pembelajaran Cooperative, 22 Juni 2016. Diakses pada tanggal 14 Maret 2017 dari situs: https://iwanlukman.blogspot.co.id/model-pembelajaran-cooperative/html/

Izzaaljannah55.wordpress.com, Model Pembelajaran Cooperative Reading and Composition, 19 Mei 2013. Diakses pada tanggal 11 Maret 2017 dari situs: https://www.google.co.id/amp/s/izzaaljannah55.wordpress.com/modelpembelajaran-cooperative-reading-and composition/amp/

Journal Miss Greget.html, MMP (Membaca dan Menulis Permulaan). Diakses pada tanggal 15 Maret 2017 dari situs: MMP (Membaca dan Menulis Permulaan) Journal Miss Greget.html.

Kunandar. 2008. Langkah Mudah Penelitian Tindakan Kelas Sebagai Pengembangan Profesi Guru. Jakarta: Raja Grafindo Persada.

Mardiatiaceh.wordpress.com. (2013, 11 Mei). Membaca Permulaan. Diperoleh 7 Maret 2017, dari https://www.google/amp/s/madiatiaceh.wordpress.com/ membaca-permulaan/amp/

Masnur Muslich. 2013. Melaksanakan PTK itu Mudah. Jakarta: Bumi Aksara. Miftahul Huda. 2013. Cooperative Learning Metode, Teknik, Struktur, dan Model Penerapan. Yogyakarta: Pustaka Pelajar.

Mulyono Abdurrahman. 2003. Pendidikan Bagi Anak Berkesulitan Belajar. Jakarta: Rineka Cipta.

Razali. 2007. Pembelajaran Bahasa Indonesia. Banda Aceh: Universitas Syiah Kuala.

Robert E. Slavin. 2009. Cooperative Learning Teori, Riset, dan Praktik. Bandung: Nusa Media.

Rostina Thaib dan Nuraini. 2007. Pembelajaran Bahasa Indonesia. Banda Aceh: Universitas Syiah Kuala.

Suharsimi Arikunto. 2011. Dasar-dasar Evaluasi Pendidikan. Jakarta: Bumi Aksara. Suharsimi Arikunto. 2011. Penelitian Tindakan Kelas. Jakarta: Bumi Aksara.

Sukardi. 2004. Metodologi Penelitian, Kompetensi, dan Prakteknya. Jakarta: Bumi Aksara.

Team Pustaka Phoenix. 2007. Kamus Bahasa Indonesia Kontemporer. Jakarta: Pustaka Phoenix.

W. J. S. Poerwadarminta. 2001. Kamus Umum Bahasa Indonesia. Jakarta: Balai Pustaka.

Wina Sanjaya. 2008. Strategi Pembelajaran Berorientasi Standar Proses Pendidikan. Jakarta: Kencana. 
Winci Firdaus, dkk. 2008. Bahasa Indonesia. Banda Aceh: Pusat Bahasa dan Pengembangan Tenaga Pengajar.

www.sekolahdasar.net, hakikat dan kedudukan pembelajaran, April 2012. Diakses pada tanggal 11 Maret 2017 dari situs:

www.sekolahdasar.net/2012/04/hakikat-dan-kedudukan-pembelajaran

www.sarjanaku.com/2011/06/pendekatan- kualitatif html. Diakses pada tanggal 29 Maret 2017 dari situs: www.sarjanaku.com/2011/06/pendekatankualitatif htm 